\title{
Burnout and use of HIV services among health care workers in Lusaka District, Zambia: a cross-sectional study Gina R Kruse ${ }^{1,2}$, Bushimbwa Tambatamba Chapula ${ }^{3}$, Scott Ikeda1,4, Mavis Nkhoma1, Nicole Quiterio, ${ }^{1,5}$, Debra Pankratz', Kaluba Mataka1, Benjamin H Chi1,6, Virginia Bond ${ }^{7,8}$ and Stewart E Reid*1,9
}

\begin{abstract}
Address: ${ }^{1}$ Centre for Infectious Disease Research in Zambia (CIDRZ), Lusaka, Zambia, ${ }^{2}$ Department of Medicine, Massachusetts General Hospital, Boston, Massachusetts, USA, ${ }^{3}$ Lusaka District Health Management Team, Zambian Ministry of Health, Lusaka, Zambia, ${ }^{4}$ Department of Family and Social Medicine, Montefiore Medical Center, Bronx, New York, USA, ${ }^{5}$ Department of Pediatrics, The Bristol Myers Squibb Children's Hospital, Robert Wood Johnson University Hospital, New Brunswick, New Jersey, USA, ${ }^{6}$ Schools of Medicine and Public Health, HIV/AIDS Research in Africa, Department of Obstetrics and Gynecology, University of Alabama at Birmingham, Birmingham, Alabama, USA, ${ }^{7 Z A M B A R T ~ P r o j e c t, ~}$ Ridgeway Campus, Ridgeway, Lusaka, Zambia, ${ }^{8}$ Health Policy Unit, Department of Public Health and Policy, London School of Hygiene and Tropical Medicine, London, UK and ' ${ }^{5}$ chool of Medicine, Division of Infectious Disease, University of Alabama at Birmingham, Birmingham, Alabama, USA

Email: Gina R Kruse - gkruse@partners.org; Bushimbwa Tambatamba Chapula - bushitamba@doctors.org.uk; Scott Ikeda - scott.ikeda@gmail.com; Mavis Nkhoma - mavis.nkhoma@cidrz.org; Nicole Quiterio - nicole.quiterio@gmail.com; Debra Pankratz - debra.pankratz@cidrz.org; Kaluba Mataka - kaluba.mataka@cidrz.org; Benjamin H Chi - benjamin.chi@cidrz.org; Virginia Bond - gbond@zambart.org.zm; Stewart E Reid* - stewart.reid@cidrz.org

* Corresponding author
\end{abstract}

Published: I 3 July 2009

Human Resources for Health 2009, 7:55 doi:10.1186/1478-449/-7-55
Received: 20 February 2009

Accepted: 13 July 2009

This article is available from: http://www.human-resources-health.com/content/7///55

(c) 2009 Kruse et al; licensee BioMed Central Ltd.

This is an Open Access article distributed under the terms of the Creative Commons Attribution License (http://creativecommons.org/licenses/by/2.0), which permits unrestricted use, distribution, and reproduction in any medium, provided the original work is properly cited.

\begin{abstract}
Background: Well-documented shortages of health care workers in sub-Saharan Africa are exacerbated by the increased human resource demands of rapidly expanding HIV care and treatment programmes. The successful continuation of existing programmes is threatened by health care worker burnout and HIV-related illness.

Methods: From March to June 2007, we studied occupational burnout and utilization of HIV services among health providers in the Lusaka public health sector. Providers from 13 public clinics were given a 36-item, selfadministered questionnaire and invited for focus group discussions and key-informant interviews.

Results: Some 483 active clinical staff completed the questionnaire (84\% response rate), 50 staff participated in six focus groups, and four individuals gave interviews. Focus group participants described burnout as feeling overworked, stressed and tired. In the survey, $51 \%$ reported occupational burnout. Risk factors were having another job (RR I.4 95\% Cl I.2-I.6) and knowing a co-worker who left in the last year (RR I.6 95\% Cl I.3-2.2). Reasons for co-worker attrition included: better pay (40\%), feeling overworked or stressed (21\%), moving away (16\%), death (8\%) and illness (5\%). When asked about HIV testing, 370 of $456(81 \%)$ reported having tested; 240 $(50 \%)$ tested in the last year. In contrast, discussion groups perceived low testing rates. Both discussion groups and survey respondents identified confidentiality as the prime reason for not undergoing HIV testing.

Conclusion: In Lusaka primary care clinics, overwork, illness and death were common reasons for attrition. Programmes to improve access, acceptability and confidentiality of health care services for clinical providers and to reduce workplace stress could substantially affect workforce stability.
\end{abstract}




\section{Background}

Over the past decade, access to antiretroviral therapy (ART) has grown at an unprecedented rate in sub-Saharan Africa, with tremendous health gains observed among those utilizing these services [1-3]. As programmes have expanded, availability of trained health personnel has become an important limiting factor in the provision of services [4-6].

Nowhere is the shortage more noticeable than in subSaharan Africa, where patient: provider ratios fall significantly below World Health Organization recommendations. In 2006, for example, an estimated 2.3 health care workers served every 1000 people in the region. This figure is below the worldwide average of 9.3 per 1000 and below the level defined as a critical shortage: 2.5 per 1000 , at which populations fail to achieve $80 \%$ coverage of services such as deliveries and vaccinations [7].

Numerous approaches have been implemented to compensate for the shortage. These include task shifting $[8,9]$, employment of lay health workers $[10,11]$ and use of technology (e.g. mobile phones or the Internet) to facilitate care and consultation [11,12]. Few strategies, however, have focused on maintaining the well-being of existing workers [13]. It is crucial that this human resource foundation be kept intact if service provision is to continue in these resource-constrained settings.

In settings with high HIV prevalence, related morbidity and mortality are responsible for health provider absenteeism and attrition. In Zambia, mortality rates are high and before ART was available, death was a common cause of attrition among district health care workers [14,15]. A recent South African survey measured HIV prevalence among health care workers at $12 \%$ [16]. In Malawi, the death rate among health care workers was $2 \%$; the most common causes were TB and other chronic illness attributable to AIDS [17].

Perhaps more overlooked is the issue of occupational burnout among health personnel, a phenomenon characterized by exhaustion, depersonalization and inefficacy [18]. The emotional intensity of caring for HIV-infected patients, along with the high patient volumes seen at many ART centres, may place health providers at particular risk for burnout [19]. The consequences can be severe and include exhaustion, reduced productivity, decreased empathy for patients, absenteeism and desire to search out other occupations $[20,21]$.

\section{Methods}

We designed a two-part study to describe occupational burnout and utilization of HIV services among providers in the primary care centres of the Lusaka, Zambia, public health sector, where services for HIV care and treatment have rapidly expanded since 2004 [3]. We recruited physicians, clinical officers (the equivalent of physician assistants in the United States and Europe), nurses, midwives and pharmacy staff employed at government clinics. Thirteen sites were chosen, all providing long-term HIV care and treatment. At each facility, other primary care services are provided, including general outpatient care, antenatal services, child health services and tuberculosis treatment. Characteristics of each facility and catchment size are shown in Table 1.

This study included qualitative and quantitative study components. Our qualitative methods consisted of six focus group discussions and four key-informant interviews. One group session was held for each of the following: midwives, physicians, clinical officers and pharmacy staff. Two groups of nurses were convened, as they comprise the vast majority of health care workers. Participants were stratified according to clinic of employment and professional cadre, and then randomly selected. Overall, 13 invitations were sent out for each group (i.e. one representative per clinic).

Discussions were held in a private conference room at a local nongovernmental organization and each lasted approximately 90 minutes. Trained study staff served as facilitators; written notes and tape recordings were transcribed.

Key informants were identified by physicians based at the study clinics and were recruited to participate in one-onone interviews. The four interviews included two providers living with HIV, one HIV-negative and one with unknown HIV status. Each lasted approximately 60 minutes.

Data were analyzed by manually compiling common themes and matrices and discussing these data between investigators, study staff and representatives from the Lusaka District Health Management Team.

In parallel, we surveyed active health care providers across the 13 clinics to quantify their perceptions of occupational burnout and HIV service utilization. All staff reporting to work over a three-week window were asked by their supervising nurse managers to complete a 36-question survey. Each questionnaire had a statement of consent attached; completion of this consent was necessary for inclusion in the analysis. Drop boxes were provided so that participants could return their questionnaires anonymously.

In the survey, prevalence of occupational burnout was based on a single question that has been validated against 
Table I: District health facilities in Lusaka, Zambia, that served as sites for this study, March 2007 to July 2007

\begin{tabular}{|c|c|c|c|c|}
\hline Clinic & Clinic catchment size & $\begin{array}{l}\text { Staff per } 10000 \text { patients in } \\
\text { catchment area }\end{array}$ & $\begin{array}{c}\text { Number of active staff during } \\
\text { study period }\end{array}$ & $\begin{array}{l}\text { Number of survey } \\
\text { respondents (\%) }\end{array}$ \\
\hline Bauleni & 69899 & 6.29 & 44 & $26(59 \%)$ \\
\hline Chawama & 117083 & 4.10 & 48 & $48(100 \%)$ \\
\hline Chelstone & 93065 & 6.88 & 64 & 57 (89\%) \\
\hline Chilenje & 98881 & 4.65 & 46 & $46(100 \%)$ \\
\hline Chipata & 140464 & 2.78 & 39 & $39(100 \%)$ \\
\hline George & 131774 & 3.04 & 40 & $35(88 \%)$ \\
\hline Kabwata & 80212 & 3.74 & 30 & $30(100 \%)$ \\
\hline Kalingalinga & 62566 & 8.95 & 56 & 25 (44\%) \\
\hline Kamwala & 97191 & 4.53 & 44 & 33 (75\%) \\
\hline Kanyama & 139597 & 4.01 & 56 & 43 (76\%) \\
\hline Matero Main & 98650 & 2.33 & 23 & $20(86 \%)$ \\
\hline Matero Ref & 106160 & 4.14 & 44 & 42 (95\%) \\
\hline Mtendere & 73565 & 5.30 & 39 & $39(100 \%)$ \\
\hline Overall & | 309107 & 4.38 & 573 & $483(84 \%)$ \\
\hline
\end{tabular}

a full occupational burnout scale [22]. Respondents were asked to quantify their level of burnout from a five-item scale: (1) "I have no symptoms of burnout"; (2) "Sometimes I am under stress, but I don't feel burned out"; (3) "I am definitely burned out and have occasional symptoms of burnout"; (4) "The symptoms of burnout I'm experiencing won't go away"; and (5) "I feel completely burned out and I am at the point where I need to make some changes or seek some sort of help". If respondents selected (3), (4), or (5) from the scale, they were categorized as having occupational burnout. We also asked numerous supporting questions to better understand types of burnout in this population.

To determine utilization of HIV services, we relied primarily on use of HIV testing services over the past 12 months. Information regarding demographic characteristics, employment history and HIV knowledge and perceptions was also collected.

In our statistical analysis, we calculated unadjusted and adjusted relative risks (RR) with 95\% confidence intervals (95\% CI) to identify predictors of occupational burnout and HIV service utilization [23]. We adjusted for individual and clinic-level variation in hierarchical logistic models by means of the SAS GLIMMIX Procedure [24]. Covariates included demographics and other independent variables associated with the outcome at $p<0.10$ in unadjusted models. All analyses were performed with SAS version 9.1.3 for Windows (Cary, North Carolina, United States of America).

All participants provided written informed consent to participate. This study was approved by the University of Zambia Research Ethics Committee and the University of Alabama at Birmingham Institutional Review Board.

\section{Results}

In May 2007, 78 individuals were invited for focus group discussions. Fifty (64\%) participated: 18 nurses, eight midwives, nine clinical officers, five medical officers and 10 pharmacy staff. Key informants comprised two registered nurses, one nurse manager and one clinical officer.

From March to July 2007, 483 of 573 active health care providers in the 13 clinics completed the study question- 
naire ( $84 \%$ response rate). Demographic characteristics are shown in Table 2 . The vast majority was female (87\%) and the overall median age was 37 (IQR: 31 to 45 years). The median time spent in the district service was 10 years (IQR: 4 to 17 years).

Table 2: Demographic and employment characteristics of survey participants $(\mathbf{N}=\mathbf{4 8 3})$

\begin{tabular}{|c|c|c|}
\hline Variables & $\mathbf{N}$ & n (\%) \\
\hline Provider type & 463 & \\
\hline Physician & & $7(1.5 \%)$ \\
\hline Clinical officer & & $50(10.8 \%)$ \\
\hline Nurse & & $234(50.5 \%)$ \\
\hline Midwife & & $129(27.9 \%)$ \\
\hline Pharmacy technician & & $19(4.1 \%)$ \\
\hline Other type & & $24(5.2 \%)$ \\
\hline Age in years, median (IQR) & 451 & $37(3 \mid-45)$ \\
\hline Female & 478 & $4 \mid 4(86.6 \%)$ \\
\hline Years in present job position, median (IQR) & 451 & $10(4-17)$ \\
\hline Department & 454 & \\
\hline Maternal and child health & & $76(16.7 \%)$ \\
\hline Outpatient & & $182(40.1 \%)$ \\
\hline ART clinic & & $49(10.8 \%)$ \\
\hline Inpatient & & $50(11.0 \%)$ \\
\hline Labor ward & & $64(14.1 \%)$ \\
\hline Other & & $33(7.3 \%)$ \\
\hline Marital status & 479 & \\
\hline Married & & $332(69.3 \%)$ \\
\hline Widowed & & $64(13.4 \%)$ \\
\hline Divorced & & $18(3.8 \%)$ \\
\hline Single & & 65 (13.6\%) \\
\hline
\end{tabular}

\section{Occupational burnout}

In our qualitative work, participating health providers related occupational burnout to feelings of being overworked, stressed and tired. Key informants characterized occupational burnout as having low energy levels, being irritable, providing poor treatment, acting rude towards patients, being more prone to mistakes and getting physically sick. Focus group participants attributed their burnout to poor working conditions. They noted long hours and heavy workload: clinical officers reported seeing more than 100 patients in a day.

Low salaries and benefits were a consistent source of frustration. Participants found their salary difficult to survive on and many took on additional jobs, which further exacerbated feelings of burnout. One key informant reported owning a small shop in addition to working nights at the general clinic and mornings at the ART clinic.

These feelings led many government workers to seek "greener pastures," such as private facilities, nongovernmental organizations or other countries where conditions were perceived to be better. It was noted that most health care workers stayed only one to three years before moving on. It was noted that when people leave, more work falls on those remaining.

In the quantitative survey, occupational burnout was noted across numerous metrics. Approximately half of respondents met our definition for occupational burnout. Nearly one quarter of respondents reported feeling too burnt-out to go to work at least once per week. When asked why their co-workers left their positions, the most common reasons were better pay (40\%) and because they felt constantly overworked or stressed in their current position (21\%), a manifestation of occupational burnout (Table 3). In hierarchical models, significant risk factors for occupational burnout are shown in Table 4 .

\section{Utilization of HIV services}

In qualitative discussions, focus group participants believed that few health care workers had been tested for HIV. When asked to try to quantify this, participants estimated that between $25 \%$ and $50 \%$ of their colleagues were aware of their HIV status. There was widespread belief that staff members do not seek testing at their clinic of employment, but instead go elsewhere to seek services (e.g. private clinics and nongovernmental organizations). A few participants also reported self-testing for HIV among health care providers, without recommended preand post-test counseling.

According to focus group participants, the main reason health providers fail to undergo HIV testing was concern over confidentiality. Every focus group acknowledged a 
Table 3: Survey respondent experiences with occupational burnout

\begin{tabular}{|c|c|c|}
\hline Questionnaire Item & $\mathbf{N}$ & n (\%) \\
\hline Using your own definition of 'burnout', please circle one of the following: & 422 & \\
\hline I have no symptoms of burnout. & & $29(6.9 \%)$ \\
\hline Sometimes I am under stress, but I don't feel burned out. & & $177(42.0 \%)$ \\
\hline I am definitely burning out and have occasional symptoms of burnout. & & $98(23.3 \%)$ \\
\hline The symptoms of burnout that I'm experiencing won't go away. & & $18(4.3 \%)$ \\
\hline I feel completely burned out. I am at the point where I need to make some changes or seek some sort of help. & & $99(23.5 \%)$ \\
\hline I am so burned out that I cannot manage to go for work. & 427 & \\
\hline Never & & $134(31.4 \%)$ \\
\hline A few times a year & & $101(23.7 \%)$ \\
\hline Once a month & & $52(12.2 \%)$ \\
\hline Once a week & & $66(15.5 \%)$ \\
\hline Every Day & & $45(10.5 \%)$ \\
\hline I have become harsh towards my patients. & 437 & \\
\hline Never & & $201(46.0 \%)$ \\
\hline A few times a year & & $123(28.2 \%)$ \\
\hline Once a month & & 17 (3.9\%) \\
\hline Once a week & & $30(6.9 \%)$ \\
\hline Every Day & & 17 (3.9\%) \\
\hline I do not feel I can sympathize with my clients & 397 & \\
\hline Never & & $229(57.7 \%)$ \\
\hline A few times a year & & $58(14.6 \%)$ \\
\hline Once a month & & $13(3.3 \%)$ \\
\hline Once a week & & $12(3.0 \%)$ \\
\hline Every Day & & $25(6.3 \%)$ \\
\hline How many health care workers in your department have left their position in the last 2 years? median (IQR) & 383 & $2.0(1.0-4.0)$ \\
\hline \multicolumn{3}{|l|}{ Why did they leave? (more than one answer possible) } \\
\hline Better pay & & $431(40.2 \%)$ \\
\hline
\end{tabular}


Table 3: Survey respondent experiences with occupational burnout (Continued)

\begin{tabular}{|c|c|c|}
\hline Constantly overstressed: a type of burnout & & $94(8.8 \%)$ \\
\hline Constantly overworked: a type of burnout & & $131(12.2 \%)$ \\
\hline Moving or leaving the area & & $175(16.3 \%)$ \\
\hline Died & & $83(7.7 \%)$ \\
\hline Personal health reasons & & 57 (5.3\%) \\
\hline Do you work at another job to earn extra income? & 458 & $161(35.2 \%)$ \\
\hline I work at a private health facility & & $124(77.0 \%)$ \\
\hline I work at a non-health facility & & $7(4.3 \%)$ \\
\hline I am self-employed & & $32(19.9 \%)$ \\
\hline How much leave have you taken in the last 12 months? (mean \pm SD) & 389 & $28.7 \pm 34.8$ \\
\hline
\end{tabular}

perceived or actual lack of confidentiality by co-workers. One key informant overheard nurses discussing the circumstances surrounding her decision to seek HIV testing (i.e. her husband's illness). A medical officer observed: "In the clinic the whole staff are confidential with a patient's history, but when it comes to a clinical officer, the whole staff would be interested." Focus group participants also reported that if a health care provider were known to be living with HIV, he or she would lose the confidence of patients and his or her future employment prospects would be compromised.
Focus group participants were afraid of becoming infected with HIV at work through activities such as injections, blood collection, intravenous infusions and deliveries. Despite this concern, many felt obligated to put themselves at risk during procedures for the sake of the patient. As one nurse explained: "If you do it, you risk your life, and if you do not, the patient dies." However, every discussion group believed most HIV-infected health care workers acquired the disease through their personal life rather than occupational exposure.

Table 4: Provider-level predictors for reporting occupational burnout

\begin{tabular}{|c|c|c|c|c|}
\hline & $\begin{array}{l}\text { Burned-out } \\
\text { n (\%) }\end{array}$ & $\begin{array}{c}\text { Not burned-out } \\
\text { n (\%) }\end{array}$ & $\begin{array}{l}\text { Crude relative risk } \\
(95 \% \mathrm{Cl})\end{array}$ & $\begin{array}{c}\text { Adjusted relative risk } \\
(95 \% \mathrm{Cl}) *\end{array}$ \\
\hline Male & $16(29.6 \%)$ & $38(70.4 \%)$ & Ref & Ref \\
\hline Female & 197 (54.4\%) & $165(45.6 \%)$ & $1.8(1.3-2.9)$ & $2.0(1.1-2.7)$ \\
\hline Age $>45$ years & $39(43.3 \%)$ & $51(56.7 \%)$ & Ref & Ref \\
\hline Age $36-45$ years & 71 (55.5\%) & $57(45.5 \%)$ & $1.3(1.0-1.7)$ & $1.5(1.1-1.9)$ \\
\hline Age $26-35$ years & 75 (52.5\%) & $68(47.5 \%)$ & $1.2(0.9-1.6)$ & $1.6(1.0-2.0)$ \\
\hline Age $16-25$ years & $8(47.1 \%)$ & $9(52.9 \%)$ & I.I (0.6-I.7) & $1.8(0.9-2.2)$ \\
\hline Work another job & 91 (64.5\%) & $50(35.5 \%)$ & $1.4(1.2-1.6)$ & $1.4(1.1-1.6)$ \\
\hline Know a co-worker who left & $176(56.8 \%)$ & $134(43.2 \%)$ & $1.6(1.3-2.2)$ & $1.6(1.2-2.0)$ \\
\hline Worry about acquiring HIV at work & $189(54.5 \%)$ & $158(45.5 \%)$ & $1.5(1.1-2.2)$ & $1.3(0.7-1.8)$ \\
\hline
\end{tabular}

* Adjusted for gender, age, marital status, general health, job title, department, time in district service, working other jobs, knowing a co-worker who left, and worry about acquiring HIV at work. 
Focus group participants reported significant stigma associated with HIV. In one case, a staff member with known HIV infection used another staff member's cup. When the owner of the cup discovered this, she broke it rather than reusing it. Participants believed that stigmatization contributes to staff avoiding or delaying HIV testing.

Despite these examples, many insisted that stigma was decreasing and supported disclosure of one's status as the best way to cope with a diagnosis of HIV. Participants reported that colleagues who were open with their HIVpositive status were treated equally. However, many agreed that HIV-infected staff members were more likely to be perceived as ill and therefore given lighter work assignments. The subsequent increase in workload for others was sometimes resented.

In our survey of health providers, 52\% reported undergoing HIV testing in the last 12 months. Of these, more than half (54\%) reported having been tested in their clinic of employment (Additional file 1). When respondents who had not undergone HIV testing were asked why not, con- fidentiality was cited as the chief concern among 28 of 60 (47\%) respondents. Most respondents (87\%) worried about becoming infected with HIV during their work as a health care provider. In contrast to our focus groups, more than one third of our respondents believed that most HIVpositive health care workers were infected at work. There were fears regarding unlikely modes of transmission, including through sweat (14\%) and saliva (25\%).

Most survey respondents (87\%) reporting knowing at least one health worker infected with HIV, usually after the colleague directly disclosed his or her HIV status. However, other modes of disclosure were reported that involved breaches of confidentiality (Additional file 1). One hundred ninety-five of $474(41 \%)$ had personally witnessed health providers gossiping about a patient's HIV status. In multivariate models, work in the ART clinic $(\mathrm{RR}=1.4,95 \% \mathrm{CI}=1.0-1.6)$ and worry about becoming infected with HIV during their work $(\mathrm{RR}=1.8,95 \% \mathrm{CI} 1.2$ - 2.2) were significantly associated with HIV testing (Table 5).

Table 5: Provider-level predictors for undergoing an HIV test over the 12 months

\begin{tabular}{|c|c|c|c|c|}
\hline & $\begin{array}{l}\text { Tested } \\
\text { n (\%) }\end{array}$ & $\begin{array}{l}\text { Not tested } \\
\text { n (\%) }\end{array}$ & $\begin{array}{l}\text { Crude relative risk } \\
\qquad(95 \% \mathrm{Cl})\end{array}$ & $\begin{array}{c}\text { Adjusted relative risk } \\
(95 \% \mathrm{Cl})^{*}\end{array}$ \\
\hline Male & $30(50.0 \%)$ & $30(50.0 \%)$ & Ref & Ref \\
\hline \multirow[t]{2}{*}{ Female } & $207(52.0 \%)$ & 191 (48.0\%) & $1.0(0.8-1.4)$ & I.I (0.7-I.5) \\
\hline & $57(58.8 \%)$ & $40(41.2 \%)$ & Ref & Ref \\
\hline Age $36-45$ years & $49(36.3 \%)$ & $86(63.7 \%)$ & $0.6(0.5-0.8)$ & $0.6(0.4-0.9)$ \\
\hline Age $26-35$ years & $96(57.1 \%)$ & $72(42.9 \%)$ & $1.0(0.8-1.2)$ & $\mathrm{I} .0(0.7-1.3)$ \\
\hline Age $16-25$ years & 14 (82.4\%) & $3(17.7 \%)$ & I.4 (I.0-I.7) & I.5 (I.0-I.7) \\
\hline Age $>45$ years & 91 (52.9\%) & 81 (47.1\%) & Ref & Ref \\
\hline ART clinic & $30(63.8 \%)$ & $17(36.2 \%)$ & $1.2(0.9-1.5)$ & $1.4(1.0-1.6)$ \\
\hline Inpatient department & $21(47.7 \%)$ & $23(52.3 \%)$ & $0.9(0.6-1.2)$ & $0.9(0.5-1.3)$ \\
\hline Maternal child health & $42(56.0 \%)$ & $33(44.0 \%)$ & I.I (0.8-I.3) & I.I (0.6-I.5) \\
\hline Labor ward & $26(40.6 \%)$ & $38(59.4 \%)$ & $0.8(0.5-1.0)$ & $\mathrm{I} .0(0.5-1.5)$ \\
\hline Other department & $16(50.0 \%)$ & $16(50.0 \%)$ & $0.9(0.6-1.3)$ & I.4 (0.7-I.7) \\
\hline Worry about acquiring HIV at work & $213(54.8 \%)$ & $176(45.2 \%)$ & $1.5(1.1-2.2)$ & $1.8(1.2-2.2)$ \\
\hline Know coworker has HIV because he/she told me & I 58 (54.3\%) & $133(45.7 \%)$ & I.I (0.9-I.4) & $1.2(1.0-1.4)$ \\
\hline
\end{tabular}

* Adjusted for gender, age, marital status, general health, job title, department, worry about acquiring HIV at work, and knowing a coworker has HIV because he/she disclosed to them. 


\section{Discussion}

In this study, we found a high prevalence of occupational burnout among district health staff. Over half met our screening definition, with most reporting numerous symptoms. Conditions of service were the most commonly cited causes of occupational burnout and attrition. Only half of our respondents reported having been tested for HIV in the past 12 months, despite the widespread availability of such services in the clinic of employment and "stand-alone" testing sites in the community. Stigma remained a significant reason why health care workers avoided HIV testing; it continued to serve as a barrier to widespread HIV testing among providers.

A strength of this study was its combination of qualitative and quantitative methods. This allowed us to "triangulate" data from multiple sources and provide comprehensive descriptions of our topics of interest. Our primary limitation is external validity. We do not know the degree to which our findings are specific to the primary care clinics of the Lusaka public health sector; however, we believe the themes are applicable to other urban African settings. We are also aware of potential reporting bias, particularly in descriptions of occupational burnout. Focus group participants were familiar with the phenomenon of burnout, likely due to prior district-sponsored workshops on the topic. In addition, all participants were informed that this study was designed to inform district policy. These conditions may have provided incentives for staff to overestimate burnout prevalence.

Occupational burnout was prevalent in this population of government health workers in these Lusaka primary care facilities. One significant predictor for occupational burnout was knowing a co-worker who had left government service. Those who remain are left with more stressful conditions, putting them at risk for burnout. This is a cycle that deserves further investigation, given its potential for exacerbating the burnout phenomenon in settings where health staff are limited. Furthermore, patients may suffer in this process, as both occupational burnout and low staffing levels have been associated with a decline in quality of care $[21,25]$. Measuring the effect of health care provider burnout on patient outcomes is an important area for future research, with powerful implications for maintaining HIV care and treatment programmes.

More than half of our survey respondents had been tested for HIV over the past 12 months. Although this figure is higher than from other reports in the region $[26,27]$, it was below our expectations. Nearly one quarter said they had "not had the opportunity to test" for HIV, despite the availability of services across numerous different testing venues (e.g. public clinics, private facilities and standalone testing centres).
Participants in both study components conveyed worry over accidental disclosure of HIV infection. Ironically, this fear of disclosure has made utilization of HIV services more difficult for these ministry employees, since their familiarity with clinic staff may make them vulnerable to breaches in confidentiality, speculation and gossip. Confidentiality and gossip have been recognized as deterrents to HIV testing among general populations [28]. Clinic staff working to provide ART were more likely to seek testing for HIV, when compared to those from other departments. This may be related to reduced stigma within this department or greater concern over HIV transmission from infected patients.

The role of occupational exposure in HIV acquisition was inconsistent between our qualitative and quantitative components. Focus groups attributed HIV infection among providers to non-work-related risk factors (75\% to $90 \%$ ) while about $40 \%$ of survey respondents believed that occupational exposure was the major route of transmission. This discrepancy may be partially attributed to misconceptions by survey respondents that HIV could be transmitted by sweat or saliva. If health care workers perceive themselves to be at high risk for HIV infection based on these misconceptions, it could adversely affect their likelihood of seeking testing. A study among Zambian women found that women reporting high personal risk for infection were less likely to accept testing at antenatal facilities [29].

Despite their roles in providing care for HIV-infected patients, health staff may have persistent misinformation and misconceptions about the disease [30]. In our survey, for example, nearly all respondents stated that HIVinfected individuals should be treated with the same respect as those who are not infected. At the same time, large proportions blamed promiscuous men or prostitutes for spreading the epidemic. While the opposing nature of these views may be subtle, they do speak to underlying and persistent stigma - even among health providers.

The overall goal of this study was to further inform district policy regarding workplace conditions. These results have been formally presented to clinic nurse managers and the Lusaka District Health Management Team. The ensuing discussion resulted in numerous recommendations that are currently being considered at the district level. To combat occupational burnout, district staff suggested workshops to teach individuals to identify burnout and develop coping mechanisms.

To improve utilization of HIV-related health services, staff emphasized the need for multiple options, since one approach was unlikely to meet the needs of all. Possibilities included: (1) parallel systems within clinics where 
staff could get care from a trusted provider; (2) a central HIV/AIDS clinic for staff; or (3) a central comprehensive health care clinic for staff, offering both ART and general care.

Peer support groups for HIV-infected health care providers were functioning in one clinic; this was seen as a success and it was suggested that other clinics implement this strategy. Ongoing initiatives to combat confidentiality breaches and HIV-associated stigma were promoted. Formal workplace HIV policies were recommended to address the unique challenges of confidentiality and stigma faced by health care workers in gaining access to HIV services.

\section{Conclusion}

As new initiatives are implemented to increase health personnel capacity in sub-Saharan Africa, existing health providers must not be overlooked. The burden of providing HIV services to large numbers of extremely ill patients is substantial and may lead to high levels of occupational burnout. Working conditions should be regularly evaluated and where possible improved, to prevent attrition related to occupational burnout. Initiatives must also focus on improving uptake of HIV testing, care and treatment services among health providers. This may require investment in locally appropriate clinical care options that will ensure confidentiality and formal workplace policies to protect those who disclose their status.

\section{Competing interests}

The authors declare that they have no competing interests.

\section{Authors' contributions}

GRK contributed to the initial study concept, protocol design, oversight, implementation, data analysis and initial drafting of the manuscript. BT contributed study oversight, implementation and critical edits to the manuscript. SI contributed to the initial study concept, protocol design, oversight and implementation and critical edits to the manuscript. MN contributed to oversight of data collection and implementation. NQ contributed to oversight and implementation and critical edits to the manuscript. DP contributed to oversight of data collection, data entry, implementation and editing the final version. KM contributed to oversight of data collection, data entry and analysis. BHC contributed to data interpretation and initial drafting and critical edits to the manuscript. VB contributed to the study design, review of the analysis and critical edits to the manuscript. SER contributed to the initial study concept, protocol design, oversight and implementation and critical edits to the manuscript. All authors read and approved the final manuscript.

\section{Additional material}

\section{Additional file 1}

Respondent experiences with HIV service use and stigma. Supplementary table outlining the HIV service use and stigma experiences of respondents.

Click here for file

[http://www.biomedcentral.com/content/supplementary/14784491-7-55-S1.doc]

\section{Acknowledgements}

The authors thank our study participants for their support and cooperation. We thank Mary Banda (Lusaka Urban District Health Management Team) and Graham Samungole (Lusaka Urban District Health Management Team) for their assistance in study implementation and recruitment. We thank Moffat Zulu and Martin Daka of CIDRZ for providing data management and data entry assistance. We acknowledge the Zambian Ministry of Health for consistent and high-level support of operations research in the context of HIV programme expansion. Investigators were supported by the Fogarty International Center (KOI-TW06670) and the Doris Duke Clinical Scientist Award (200706I). Additional support was provided by the Department for International Development (DFID), United Kingdom Research Programme Consortia, Team for Applied Research Generating Effective Tools and Strategies for Communicable Disease Control (TARGETS) and Evidence for Action (EFA).

\section{References}

I. Bussmann H, Wester CW, Ndwapi N, Grundmann N, Gaolathe T, Puvimanasinghe J, et al: Five-year outcomes of initial patients treated in Botswana's National Antiretroviral Treatment Program. AIDS 2008, 22(I7):2303-II.

2. Ferradini L, Jeannin A, Pinoges L, Izopet J, Odhiambo D, Mankhambo $L$, et al.: Scaling up of highly active antiretroviral therapy in a rural district of Malawi: an effectiveness assessment. Lancet 2006, 367(95 I 9): 1335-42.

3. Stringer JS, Zulu I, Levy J, Stringer EM, Mwango A, Chi BH, Mtonga V, Reid S, et al: Rapid scale-up of antiretroviral therapy at primary care sites in Zambia: feasibility and early outcomes. JAMA 2006, 296(7):782-93.

4. Kober K, Van Damme W: Scaling up access to antiretroviral treatment in southern Africa: who will do the job? Lancet 2004, 364(9428): 103-7.

5. Kuehn BM: Global shortage of health workers, brain drain stress developing countries. JAMA 2007, 298(16): 1853-5.

6. Samb B, Celletti F, Holloway J, Van Damme W, De Cock KM, Dybul $M$ : Rapid expansion of the health workforce in response to the HIV epidemic. N Engl J Med 2007, 357(24):2510-4.

7. WHO: "Working together for health" in The World Health Report 2006. Geneva, World Health Organization; 2006.

8. Dovlo D: Using mid-level cadres as substitutes for internationally mobile health professionals in Africa. A desk review. Hum Resour Health 2004, 2(I):7.

9. Mullan F, Frehywot S: Non-physician clinicians in 47 sub-Saharan African countries. Lancet 2007, 370(9605):2158-63.

10. Schneider $\mathrm{H}$, Hlophe $\mathrm{H}$, van Rensburg $\mathrm{D}$ : Community health workers and the response to HIVIAIDS in South Africa: tensions and prospects. Health Policy Plan 2008, 23(3): 179-87.

II. Chang LW, Kagaayi J, Nakigozi G, Packer AH, Serwadda D, Quinn $\mathrm{TC}$, et al: Responding to the human resource crisis: peer health workers, mobile phones, and HIV care in Rakai, Uganda. AIDS Patient Care 2008, 22(3): 173-4.

12. Skinner D, Rivette U, Bloomberg C: Evaluation of use of cellphones to aid compliance with drug therapy for HIV patients. AIDS Care 2007, 19(5):605-7.

13. Uebel KE, Nash J, Avalos A: Caring for the caregivers: models of HIVIAIDS care and treatment provision for health care 
workers in Southern Africa. I Infect Dis 2007, 196(Suppl 3):S500-4.

14. Buve A, Foaster SD, Mbwili C, Mungo E, Tollenare N, Zeko M: Mortality among female nurses in the face of the AIDS epidemic: a pilot study in Zambia. Aids 1994, 8(3):396.

15. Feeley R, Rosen S, Fox M, Macwan'gi M, Mazimba A: The cost of HIVIAIDS Among Professional Staff in the Zambian Public Health Sector. Lusaka, Zambia. U.S. Agency for International Development; 2004.

16. Connelly D, Veriava Y, Roberts S, Tsotetsi J, Jordan A, DeSilva E, Rosen S, DeSilva MB: Prevalence of HIV infection and median CD4 counts among health care workers in South Africa. SAfr Med J 2007, 97(2): I I5-20.

17. Harries AD, Hargreaves NJ, Gausi F, Kwanjana JH, Salaniponi FM: High death rates in health care workers and teachers in Malawi. Trans R Soc Trop Med Hyg 2002, 96(I):34-7.

18. Maslach C, Schaufeli WB, Leiter MP: Job burnout. Annu Rev Psychol 200I, 52:397-422

19. Bennett L, Michie P, Kippax S: Quantitative analysis of burnout and its associated factors in AIDS nursing. AIDS Care 199I, 3(2): $18 \mid-92$.

20. Estryn-Behar M, Heijden BI Van der, Oginska H, Camerino D, Le Nezet $O$, Conway PM, et al.: The impact of social work environment, teamwork characteristics, burnout, and personal factors upon intent to leave among European nurses. Med Care 2007, 45(10):939-50.

21. Aiken LH, Clarke SP, Sloane DM, Sochalski J, Silber JH: Hospital nurse staffing and patient mortality, nurse burnout, and job dissatisfaction. JAMA 2002, 288( (16): 1987-93.

22. Williams ES, Konrad TR, Linzer M, McMurray J, Pathman DE, Gerrity $M$, et al:: Physician, practice, and patient characteristics related to primary care physician physical and mental health: results from the Physician Worklife Study. Health Serv Res 2002, 37(I): $121-43$

23. Zhang J, Yu KF: What's the relative risk? A method of correcting the odds ratio in cohort studies of common outcomes. JAMA 1998, 280(19):1690-I.

24. Brown H, Prescott $\mathrm{H}$ : Applied mixed models in medicine New York: John Wiley \& Sons; 2006.

25. Needleman J, Buerhaus P, Mattke S, Stewart M, Zelevinsky K: Nursestaffing evels and the quality of care in hospitals. $N$ Engl $J$ Med 2002, 346(22): $1715-22$

26. Tarwireyi $F$, Majoko $F$ : Health workers' participation in voluntary counselling and testing in three districts of Mashonaland East Province, Zimbabwe. Cent Afr J Med. 2003, 49(5-6):58-62.

27. Dieleman M, Biemba G, Mphuka S, Sichinga-Sichali K, Sissolak D, Kwaak $A$ van der, et al:: 'We are also dying like any other people, we are also people': perceptions of the impact of HIVI AIDS on health workers in two districts in Zambia. Health Policy Plan 2007, 22(3): 139-48.

28. Hutchinson PL, Mahlalela X: Utilization of voluntary counseling and testing services in the Eastern Cape, South Africa. AIDS Care 2006, 18(5):446-55.

29. Thierman S, Chi BH, Levy JW, Sinkala M, Goldenberg RL, Stringer JS Individual-level predictors for HIV testing among antenatal attendees in Lusaka, Zambia. Am J Med Sci 2006/07//8 edition 2006, 332(I): 13-7.

30. Chi BH, Chansa K, Gardner MO, Sangi-Haghpeykar H, Goldenberg RL, Sinkala M, Muchimba M, stringer JS: Perceptions toward HIV, HIV screening, and the use of antiretroviral medications: a survey of maternity-based health care providers in Zambia. Int J STD AIDS 2004, I5(10):685-90.

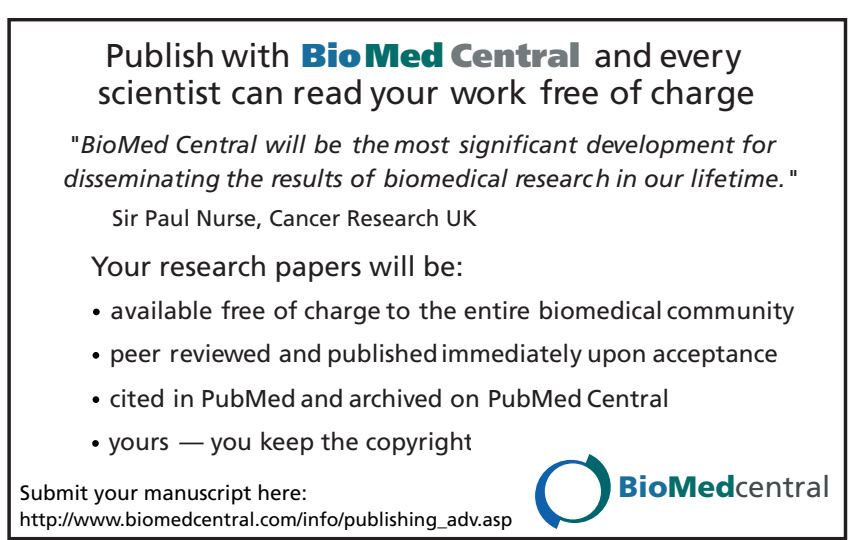

